\title{
Deleuze e Proust: tempo, signo e pensamento
}

Leonardo Araújo

\section{Resumo:}

O presente texto expõe uma reconstrução da abordagem do filósofo Gilles Deleuze sobre a obra literária de Marcel Proust. Deleuze encontra no texto de Proust temas fundamentais para sua própria filosofia: o signo, o tempo e o pensamento. $O$ atrelamento desses temas forja uma nova concepção do próprio tempo e, principalmente, uma nova imagem do pensamento: não mais baseada no pressuposto de que o pensamento é algo de natural, e sim de que ele necessita de uma força exterior para se ativar. Deleuze tem como uma das principais questões de sua filosofia (e encontra em Proust um aliado) a pergunta pela gênese do pensamento.

Palavras-chave: Marcel Proust - Gilles Deleuze - pensamento - signo tempo 


\section{Introdução}

Se a filosofia, tal como a concebe Deleuze, é criação de conceitos, e desse registro se excluiriam artistas, cientistas, publicitários, etc., poderia se inferir disso que o conhecimento filosófico é de uma ordem superior a outras áreas do saber? Pelas linhas deleuzeanas de indagação, não. Estabelecer matérias específicas para seus respectivos domínios, como a função em relação à ciência e os perceptos e afetos em relação à arte, é também a garantia da ausência de hierarquia de um domínio sobre o outro, o que não implica a ausência de participação desses diferentes domínios entre si. Para Deleuze, a ciência (contrariando Heidegger) e a arte também pensam, e uma das grandes questões de sua filosofia (que é também uma questão heideggeriana) se constitui através do seguinte enunciado: o que quer dizer pensar?

É assim que a filosofia de Deleuze se agencia e estabelece alianças com diferentes áreas do saber e, principalmente, com a arte. Na literatura de Marcel Proust, Deleuze encontra grandes questões que são movidas para o interior de sua própria filosofia. Esse movimento de conceituação do não conceituado (ou não conceitual) sobre a obra de Proust leva Deleuze a investigar e abordar duas grandes questões: o tempo e o pensamento.

Porém, ainda outro elemento atua como um vetor que perpassa essas duas questões, a saber: o signo, que em Deleuze haveria de compor a temática de livros como Spinoza et le problème de l'expression (I968), Cinema 1 (I983) e Cinema 2 (I985). A temática do signo se insere em um contexto problemático abordado por Deleuze desde sua primeira obra sobre Nietzsche (Nietzsche e a filosofia, de I965), e que perpassa toda sua obra, com destaque para Diferença e repetição (I968), na qual se encontra um capítulo dedicado à questão: a imagem do pensamento.

\section{Deleuze: a filosofia e a não filosofia}

Deleuze procede por uma espécie de método de interpretação seletivo, encontrando no discurso filosófico conceitos que apropria para sua própria filosofia. Para o pensador francês, pensar a história da filosofia não deve ser uma prática de mera reprodução, mas sim um ato diferencial, de poder dizer o que um filósofo não disse, mas que, no entanto, diria segundo uma argumentação imanente ao seu pensamento e, principalmente, segundo suas motivações, intenções e intuições (foi assim, por exemplo, que detectou como motivação do célebre método da divisão platônica uma vontade de selecionar). Por isso essa argumentação imanente não se efetua por intermédio de uma dedução de 
categorias lógicas concatenadas à identidade e à representação, pois ela é da ordem das singularidades nômades e das intensidades pré-individuais: "[...] a filosofia de Deleuze trata de ligações; num certo sentido, ela é uma arte de agregar coisas múltiplas por meio de sínteses 'disjuntivas', de conjunções lógicas anteriores e irredutíveis à predicação ou à identificação" (RAJCHMAN, 2002 , p. II). São essas ligações que, para Rajchman, constituem o ponto de apoio ao estilo filosófico de Deleuze. Isso é possível na medida em que se toma o pensamento, em conteúdo e forma, como formado por sistemas abertos, desenvolvido por eixos e orientações, que se ligam menos a categorias históricas em seu sentido linear do que a uma espécie de geografia do pensamento, que privilegia a constituição de tipos em determinados lugares (topos).

Ao investigar a história das ideias, Deleuze dedicou escritos monográficos a uma série de filósofos, tais como: Lucrécio, Spinoza, Leibniz, Hume, Kant, Nietzsche, Bergson e Foucault. Uma porção considerável desses nomes é tida como filosofia de fronteira, como produção de pensamento marginal. Ao pensar a história das ideias, Deleuze estabelece uma espécie de geografia do pensamento, a considerar tipos que supõe uma certa topologia, de modo que tais filósofos, que de alguma maneira foram excluídos ou muito pouco destacados na história do pensamento ocidental, são direcionados por Deleuze em uma linha privilegiada de um espaço específico: o da imanência e da diferença.

Porém, se Deleuze conta com seus aliados filosóficos, aproveitando desses seus conceitos e concebendo a filosofia como única atividade capaz de criá-los, não exclui de sua filosofia o trabalho com o pensamento não filosófico ou exterior à filosofia; ao contrário, cria uma zona de coalescência na qual a fronteira entre filosofia e não filosofia ganha contornos cada vez mais sutis. Até mesmo porque esse exterior, esse fora, para Deleuze, é também, de alguma maneira, como que um "dentro", na medida em que é imanente a sua criação conceitual. É nessa medida que trabalhou com vários pensadores da arte, como o pintor Francis Bacon; vários cineastas, tais como Orson Welles, Alain Resnais, Jean-Luc Godard e Michelangelo Antonioni; literatos, dentre eles Franz Kafka e Marcel Proust. Partindo de campos exteriores ao conhecimento filosófico, o autor de Lógica do sentido pôde encontrar neles um campo fecundo para sua produção conceitual.

Uma das principais questões da filosofia de Deleuze pode ser formulada pela seguinte proposição interrogativa: o que significa pensar? É preciso ressaltar que o exercício do pensamento não é propriedade única da filosofia, na medida em que outros campos do saber, como a ciência e a arte, também o realizam, e por isso não estão fora do projeto filosófico de Deleuze. Porém, se o exercício de pensamento em tais campos não é conceitual e a filosofia é 
definida como criação de conceitos, como esses campos podem adentrar na filosofia? Trata-se de transformar esse exercício não conceitual em conceito. Nesse contexto é que se encontra inserida a obra Proust e os signos (I964), onde o filósofo francês pensa as questões ligadas ao signo, ao tempo e ao pensamento na obra Em busca do tempo perdido (À la recherche du temps perdu).

\section{Sobre os diferentes regimes de signos distribuídos pela busca do tempo perdido}

Deleuze propõe pensar a obra de Proust, assim como faria mais tarde com a filosofia de Spinoza e com as questões cinematográficas, como um sistema de signos. A obra Em busca do tempo perdido configura a exposição de um sistema de signos. O signo é tudo aquilo que se apresenta como algo a ser decifrado. Tudo é signo, no entanto, esses não se distribuem homogeneamente. Podemos afirmar, assim, que os signos compõem tipos diferentes. Os regimes de signos são diferentes por várias razões, dentre elas, a de que não são emitidos do mesmo modo, a de que provocam efeitos diferentes nos intérpretes, de que produzem diferentes sentidos e, principalmente, se estabelecem em relações com diferentes estruturas do tempo. Deleuze apresenta quatro desses tipos de signos: mundanos, amorosos, sensíveis e artísticos.

São nas relações sociais descritas no romance de Proust que surgem os signos mundanos. Lê-se no texto vários encontros, festas e banquetes regrados com diálogos entre grupos de burgueses e aristocratas, povoados por personagens como médicos, diplomatas e militares. Causa curiosidade nesse regime de signos como ele próprio é composto de forma heterogênea, de modo a determinar para os personagens situações em que reina a mútua falta de compreensão. Um exemplo que pode ser oferecido é o fato de que no grupo dos Verdurin não operam os mesmos signos que no grupo dos Guermantes, e vice-versa: "num domínio comum, os mundos se fecham: os signos dos Verdurin não funcionam entre os Guermantes; inversamente, o estilo de Swann ou os hieróglifos de Charlus também não funcionam entre os Verdurin" (DELEUZE, 20IO, p. 5).

Os signos do amor aparecem frequentemente no texto de Proust. O autor tem o amor como um de seus grandes temas e podemos recolher vários exemplos em sua série de romances. Dentre vários casos, Proust nos apresenta o amor de Saint-Loup por Rachel; a paixão de Charlus por Morel; a obsessão de Swann por Odette - tema principal do primeiro livro (No caminho de Swann). O amado aparece como uma pluralidade louca de signos os quais o amante 
não consegue decifrar, decodificar, o que mantém o mundo do amante inacessível ao amado, produzindo o ciúme, a obsessão, o sofrimento. Como observa Roberto Machado:

No amor, de um modo geral, o amado aparece ao amante como um signo, ou melhor, como uma pluralidade de signos, implicando, envolvendo uma pluralidade, uma multiplicidade de mundos inacessíveis, misteriosos, desconhecidos. Os signos amorosos exprimem um mundo secreto que exclui o amante e ao qual ele quer ter acesso. Daí o ciúme, daí o sofrimento dos que amam (MACHADO, 2010, p. I96).

O amado aparece como algo a ser interpretado, e o amante, precisamente pelo sentimento do amor, pelo imperialismo da paixão, sente-se forçado a interpretar, mas sempre verá no amado certos segredos, ocultações, que por sua vez expressam os espaços aos quais o amante não pode acessar, não importando se são ou se não são da intenção daquele. Vários são os exemplos de casos de ciúmes na obra de Proust. Dentre eles, o mais notável, pelo grau de obsessão elevado, é o descrito em A prisioneira, quinto romance da série, em que grande quantidade de páginas do texto é marcada com o nome de Albertine, que no campo diegético desse livro, aparece como que aprisionada em casa do narrador. No livro seguinte, A fugitiva, quando o narrador se dá conta que Albertine fugiu, logo nas primeiras linhas, vê-se abandonado, atravessado pela dor, que, no entanto, o força a pensar e realizar descobertas:

"A Senhorita Albertine foi-se embora!" Como, em psicologia, o sofrimento vai mais longe que a psicologia! Um momento antes, analisando-me, eu imaginara que tal separação sem que nos víssemos de novo era justamente o que havia desejado, e, comparando a mediocridade dos prazeres que me dava Albertine à riqueza daqueles de cuja realização ela me privava, julgara-me sutil, concluíra que não queria mais vê-la, que já não a amava. Mas estas palavras: "A Senhorita Albertine foi-se embora" acabavam de provocar no meu peito uma dor tal que eu sentia não poder suportá-la por muito tempo. Assim, o que pensara para não ser nada para mim era simplesmente toda a minha vida. Como a gente se desconhece! [...] Sim, ainda há pouco, antes da chegada de Françoise, pensara que já não amava Albertine e que não teria de renunciar a nada; como analista rigoroso, imaginara conhecer muito bem o fundo do meu coração. Mas nossa inteligência, por maior que seja, não pode perceber os elementos de que ele se compõe e que permanecem insuspeitados, enquanto, do estado volátil em que subsistem a maior parte do tempo, um fenômeno capaz de isolá-lo não os 
faça sofrer um princípio de solidificação. Eu me enganara julgando ver claramente no meu coração. Mas esse conhecimento, que as mais finas percepções do espírito não me haviam conferido, acabava de me ser proporcionado, duro, brilhante, estranho, como um sal cristalizado, pela brusca reação da dor (PROUST, 2004b, p. 3I7).

O primeiro capítulo desse livro, sobre mágoa e esquecimento, inicia partindo do acontecimento final do livro anterior, quando Françoise anuncia ao narrador que Albertine havia pedido as malas para ir embora. Aqui, o herói do romance percebe algo que escapava ao seu intelecto anteriormente, mas que lhe apareceu nesse momento com a necessidade causada pelo encontro com a dor. É um elemento comum entre os signos do amor e os signos mundanos o fato de forçarem a faculdade da inteligência a fazer descobertas, mas também o fato de que tais descobertas sejam necessariamente da ordem de certa posteridade.

Os signos sensíveis, em relação aos outros tipos, são impressões mais gerais, qualidades tiradas da natureza. O grande exemplo se encontra no primeiro livro da série, quando o personagem narrador experimenta o biscoito chamado madeleine, lhe oferecido por sua mãe:

Fazia já muitos anos que, de Combray, tudo que não fosse o teatro e o drama do meu deitar não existia mais para mim, quando num dia de inverno, chegando eu em casa, minha mãe, vendo-me com frio, propôs que tomasse, contra meus hábitos, um pouco de chá. A princípio recusei e, nem sei bem porque, acabei aceitando. Ela então mandou buscar um desses biscoitos curtos e rechonchudos chamados madeleines, que parecem ter sido moldados na valva estriada de uma concha de São Tiago. E logo, maquinalmente, acabrunhado pelo dia tristonho e a perspectiva de um dia seguinte igualmente sombrio, levei à boca uma colherada de chá onde deixara amolecer um pedaço da madeleine. Mas no mesmo instante em que esse gole, misturado com os farelos do biscoito, tocou meu paladar, estremeci, atento ao que se passava de extraordinário em mim. Invadira-me um prazer delicioso, isolado, sem a noção de sua causa. Rapidamente se me tornaram indiferentes as vicissitudes da minha vida, inofensivos os seus desastres, ilusória a sua brevidade, da mesma forma como opera o amor, enchendo-me de uma essência preciosa; ou antes, essa essência não estava em mim, ela era eu. Já não me sentia medíocre, contingente, mortal. De onde poderia ter vindo essa alegria poderosa? Sentia que estava ligada ao gosto do chá e do biscoito, mas ultrapassava-o infinitivamente, não deveria ser da mesma espécie. De onde vinha? Que significaria? Onde apreendê-la? (PROUST, 2004a, p. 5I). 
Ocorre um encontro entre o narrador e um tipo de signo, isto é, o sabor daquilo que experimentara, que o mergulha em uma imensa alegria sem objeto. De fato, não adianta provar mais vezes da composição entre madeleine e chá para desvendar o sentido do signo. Destarte, recusa-se aqui o objetivismo. Mas não é pela via subjetiva que o sentido lhe surgirá, uma vez que não é o esforço da memória voluntária, por associações de semelhança entre uma impressão presente e uma impressão passada, que revela o sentido do signo, mas sim uma lembrança que lhe aparece de súbito, que o faz recordar sua infância em Combray, quando sua tia lhe oferecia madeleines nas manhãs de domingo; porém, junto a essa lembrança o signo desenrola-se para ele na forma da cidade de Combray em toda sua inteireza: as pessoas, as ruas, a igreja, os jardins. Essa força súbita, particular do signo sensível, provém da memória involuntária. A definição de memória involuntária é estabelecida a partir da constatação de que a memória da inteligência é insuficiente enquanto meio de conhecimento e de recuperação do tempo que passou: "Mas como que na época eu lembrasse me seria fornecido exclusivamente pela memória voluntária, a memória da inteligência, e como as informações que ela nos dá do passado nada conservam dele, nunca teria sentido interesse em imaginar o resto de Combray" (PROUST, 2004a, p. 50). A memória voluntária produz uma imagem do passado segundo uma expressão de ordem cronológica do tempo, ou seja, o tempo, enquanto residir no interior do esquema da memória voluntária, aparece sob a mensuração do espaço, pois é considerado extensivo e não intensivo. Por essa razão a memória voluntária não traz conhecimento. A intensidade é o que, conceitualmente na obra de Deleuze, ocupará em outros textos o lugar do signo, uma vez que o signo já é da ordem do intensivo, de uma força produzida no pensamento, de uma violência que força a pensar. A liberação do tempo de sua face extensiva, espacial, faz com que o tempo comporte certa multiplicidade. A questão de Proust é essa ambiguidade, essa complicação, as coimplicações do tempo: "como se houvesse no tempo séries diversas e paralelas" (PROUST, 2004c, p. 625). Mas a conquista do tempo em seu estado complicado, a conquista do tempo puro, só pode ser realizada através da arte.

O quarto tipo de signo é o das artes e distribui-se, na obra Em busca do tempo perdido, basicamente em três áreas: pintura, música e literatura. Nos romances são tecidos comentários a artistas fictícios, como o pintor Elstir, o músico Vinteuil e o escritor Bergotte. Mas também são feitas considerações a pintores, músicos e literatos reais, como Manet, Wagner e Baudelaire, dentre outros. Deleuze defende a tese de que os signos artísticos são os principais para Proust, uma vez que é para o domínio da arte que todos os outros domínios convergem e é por meio dele que se compreendem todos os outros. 
No fim de O tempo recuperado (ou Tempo redescoberto), último livro da série, o narrador descobre que todo o tempo que anteriormente considerava perdido, mormente pelas paixões e falatórios sociais (encontros com signos amorosos e signos mundanos), lhe serviria para que, finalmente, escrevesse a sua obra.

Cada regime de signos possui uma relação própria com o tempo, relações essas reveladas pelo último tipo de signos. A arte é que liberará o tempo em seu estado puro e trará o tempo recuperado, ou melhor, a obra de arte é o único meio pelo qual o tempo pode ser redescoberto.

A arte é que dá, inclusive, o sentido da relação dos outros tipos de signos com o tempo. Tanto no âmbito dos signos mundanos como no dos signos amorosos, a estrutura do tempo que se apresenta é a do tempo perdido, no sentido de alguém que "perde tempo". É o que se pode notar perpassando a série de livros: o narrador considerando seu tempo perdido no vazio da vida social mundana e nas relações amorosas, quando poderia estar escrevendo a sua obra. Mas essa estrutura do tempo ligada a esses dois regimes de signos, do tempo como algo perdido, se apresenta novamente de modo heterogêneo, pois se relaciona diferentemente com cada um dos tipos. No amor, em razão do ciúme, o tempo perdido é como que antecipado, já preparado para o seu fim e desaparecimento. O tempo perdido no amor, nesse sentido, é mais puramente perdido, mais irrecuperável. O que ocorre com o tempo no campo dos signos mundanos é que esse tipo de signo, embora expresse a vacuidade das relações sociais, se relaciona paralelamente com um aprendizado, que o personagem compreenderá apenas quando construir sua obra. É propriamente o vazio do tempo perdido, enquanto signo mundano, que força o pensamento, que levará o narrador a descobrir, no último volume da série, no episódio da festa em casa do príncipe de Guermantes, que o que se apreende do tempo perdido é sua própria passagem, que é da ordem da mudança, da alteração.

Como já exposto, a estrutura do tempo correspondente aos signos artísticos é a do tempo recuperado, mas tal estrutura também se identifica com a que se apresenta no signo sensível, tamanho o poder da memória involuntária. Com a ativação dessa memória, institui-se a relação entre os signos sensíveis e o tempo recuperado. Porém, o tempo recuperado, nesse contexto, ainda possui um limite, o de se ligar, se prender, ter seu correspondente material em um tempo que já foi desenvolvido.

Para Deleuze, os signos artísticos, em Proust, são ainda superiores aos signos sensíveis, uma vez que esse regime de signos, ao contrário daquele, se encontra dependente de uma matéria, de uma matéria rebelde ao espírito - e somente os signos artísticos são completamente imateriais, espirituais, o que 
lhes confere certa autonomia. A arte é o que assegura a unidade entre o signo (imaterial) e seu sentido (espiritual). É a arte o que revela a diferença absoluta. Diferença essa que, sem a arte, não se libertaria de nossa subjetividade, da condição de um eterno segredo pessoal. A arte oferece o maior grau de potência em criação; e em Deleuze, aprender é, sobretudo, criar.

Mas o que mais interessa a Deleuze em sua interpretação da literatura de Proust como um elogio a superioridade da arte, é que a recherche traz a provocadora oposição entre a arte e a filosofia. Porém, é preciso tomar a crítica de Proust à filosofia como válida, com a precaução de se considerar essa "filosofia" criticada, como componente da tradição racionalista, de cunho dogmático, ou, mais precisamente, a filosofia que oferece uma imagem dogmática do pensamento.

\section{Iv. Deleuze e Proust: crítica à imagem dogmática do pensamento}

Deleuze e Guattari definem a filosofia como criação de conceitos. Mas os conceitos só aparecem segundo uma condição interna, um solo instaurador: o plano de imanência ou imagem do pensamento. O filósofo precisa traçar seu plano de imanência para criar conceitos: "a filosofia é ao mesmo tempo criação de conceito e instauração do plano. O conceito é o começo da filosofia, mas o plano é sua instauração" (DELEUZE; GUATTARI, I997, p. 58). Além dos conceitos, o plano é povoado por elementos pré-filosóficos que dão consistência ao conceito. Destarte, devido à importância do plano ou imagem do pensamento, quando Deleuze concebe a crítica da filosofia, o faz incidindo exatamente nesse ponto. Se a produção filosófica supõe uma imagem do pensamento, o que nos mostra Deleuze, inspirado na filosofia de Nietzsche e apoiado pela literatura de Proust, é que a tradição se ergueu sobre uma imagem dogmática do pensamento.

Na obra Diferença e repetição (I968), escrita quatro anos após Proust e os signos, Deleuze investiga a relação entre a imagem dogmática do pensamento e os elementos pré-filosóficos, transmutando os postulados do pensamento, estabelecidos pela tradição dogmática, em proposições adequadas e implícitas a tal imagem.

O filósofo não clama pelos postulados como proposições que lhe devam ser concedidas, na medida em que os postulados são, eles mesmos, os temas de proposições, implícitos e entendidos de um modo e em um plano pré-filosófico. São mencionados, no livro, oito postulados: Iำ- do princípio ou 
da boa vontade do pensador e boa natureza do pensamento; $2^{\circ}-$ do ideal ou do senso comum; $3^{\circ}-$ do modelo ou da recognição; $4^{\circ}-$ do elemento ou da representação; $5^{\circ}$ - do negativo ou do erro; $6^{\circ}-$ da função lógica ou da proposição; $7^{\circ}-$ da modalidade ou das soluções; $8^{\circ}-$ do fim ou do resultado. Como os postulados entram na composição do pensamento? Conforme Deleuze, os postulados podem ser expressos em duas imagens, que, no entanto, são suprimidas, restando apenas sua expressão dogmática, silenciosamente:

Se cada postulado tem duas figuras, é porque ele é uma vez natural e uma vez filosófico; uma vez no arbitrário dos exemplos e uma vez no pressuposto da essência. Os postulados não têm necessidade de serem ditos: eles agem muito melhor em silêncio, no pressuposto da essência como na escolha dos exemplos; todos eles formam a imagem dogmática do pensamento (DELEUZE, 2006, p. I6I).

Em I962, antes de ter escrito Diferença e repetição, e mesmo anteriormente à composição de Proust e os signos, Deleuze já construíra a crítica à imagem dogmática do pensamento em Nietzsche e a filosofia, de onde se pode notar que a formulação dos oito postulados explicitados no capítulo "A imagem do pensamento" (em Diferença e repetição), tem sua raiz na ordenação de três teses que expressam tal imagem: $\mathrm{I}^{\mathrm{o}}-\mathrm{da}$ boa vontade do pensador - que o pensamento possui formalmente o verdadeiro (inatismo da ideia ou apriorismo do conceito), que a verdade é naturalmente afim do pensamento, que pensar é o exercício natural de uma faculdade. $2^{\circ}-$ sobre a exterioridade dos obstáculos ao pensamento. O pensamento seria tirado de sua reta direção sempre por forças consideradas exteriores a ele (corpo, paixões, interesses sensíveis), que o levam ao erro - considerado o efeito do embate com forças estranhas, o que resulta em tomar o falso pelo verdadeiro. $3^{\circ}-$ desse modo, seria preciso um método para se pensar bem, com o fito de encontrar a natureza do pensamento e pensar verdadeiramente. $\mathrm{O}$ método seria o artifício pelo qual se pode evitar tomar o falso pelo verdadeiro.

O centro de determinação de toda a imagem do pensamento e onde deve incidir a crítica é a concepção de que o pensamento é algo natural, que aparece naturalmente, segundo o exercício de uma faculdade e da livre e boa vontade de um pensador. Deleuze encontra a crítica efetiva primeiramente em Nietzsche. Como se pode notar nesse trecho de um aforismo de Além do bem e do mal: "Quanto à superstição dos lógicos, nunca me cansarei de sublinhar um pequeno fato que esses supersticiosos não admitem de bom grado - a saber, que um pensamento vem quando 'ele' quer, e não quando 'eu' quero" (NIETZSCHE, I999, p. 23). Pode-se observar através do trecho supracitado, 
que Nietzsche inspira Deleuze em sua crítica ao afirmar que o pensamento não depende de nosso esforço pessoal e que, portanto, não se tem controle sobre sua gênese e não é possível prever seu surgimento. Não será pela afirmação "eu penso" que passaremos direto da inatividade do pensamento para sua atividade, uma vez que "pensar designa a atividade do pensamento; mas o pensamento tem suas maneiras próprias de ser inativo, ele pode empenhar-se nisso inteiramente com todas as suas forças" (DELEUZE, I976, p. 88).

No entanto, se Nietzsche é a inspiração de Deleuze em sua crítica, não é o único aliado do pensador francês nesse projeto. Se a crítica da filosofia teria sido executada por Nietzsche do ponto de vista da própria filosofia e executada em sua totalidade (algo que, segundo Deleuze e o próprio Nietzsche, o autor inicial do projeto - Kant - não teria conseguido), haveria outras perspectivas de onde executar a crítica? Deleuze encontra a resposta em Proust: através da arte.

O privilégio que Proust oferece à arte em relação a outros domínios é aproveitado por Deleuze em sua própria crítica, pois através da arte do romancista francês, Deleuze pode apresentar a crítica por intermédio da concepção de signo. Em Nietzsche já aparecia a ideia de que o pensamento só se apresenta segundo uma força que lhe é anterior, sobre um forçamento que traz violência ao ato de pensar. Em Proust, a própria força ganha a forma do signo, é o signo que nos força a pensar:

O que nos força a pensar é o signo. O signo é objeto de um encontro; mas é precisamente a contingência do encontro que garante a necessidade daquilo que ele faz pensar. $\mathrm{O}$ ato de pensar não decorre de uma simples possibilidade natural; ele é, ao contrário, a única criação verdadeira. A criação é a gênese do ato de pensar no próprio pensamento. [...] Pensar é sempre interpretar, isto é, explicar, desenvolver, decifrar, traduzir um signo (DELEUZE, 20IO, p. 9I).

O signo é o objeto de encontro sem o qual o pensamento não seria nem mesmo pensado, é o elemento ao qual é preciso remeter como um princípio de interpretação. Se toma a imagem do pensamento como algo ligado ao plano do pré-conceitual, do pré-filosófico, não causa espanto que Deleuze, ao abordar a literatura de Proust como crítica à imagem clássica do pensamento, afirme que: "[...] sem algo que force a pensar, sem algo que violente o pensamento, este nada significa. Mais importante que o pensamento é o que 'dá que pensar'; mais importante do que o filósofo é o poeta" (DELEUZE, 20IO, p. 89; grifos do autor). Nesse ponto, Deleuze fala por Proust e sobre um território específico, o da crítica à imagem dogmática do pensamento sob o ponto de vista daquilo que força a pensar. 
Deleuze, através da literatura de Proust, opera uma mudança de local para o pensamento e a filosofia, ao retornar ao tema da gênese do pensamento ligado à emissão de signos. A tarefa do pensamento é recolocada como um exercício permanente, com sua gênese não mais atrelada aos postulados da razão. Tais postulados não apreendem o signo que, fora da condição de possibilidade que a razão ofereceria, força o pensamento a pensar. O pensamento não seria mais o exercício de uma determinada faculdade, mas o ato, precisamente, da criação que conduz à interpretação, ou melhor, da interpretação que já é, em si, criação.

O que nos força a pensar é o signo. O signo é objeto de um encontro; mas é precisamente a contingência do encontro que garante a necessidade daquilo que ele faz pensar. O ato de pensar não decorre de uma simples possibilidade natural; ele é, ao contrário, a única criação verdadeira. A criação é a gênese do ato de pensar no próprio pensamento. Ora, essa gênese implica alguma coisa que violenta o pensamento, que o tira de seu natural estupor, de suas possibilidades apenas abstratas. Pensar é sempre interpretar, isto é, explicar, desenvolver, decifrar, traduzir um signo. [...] Nem existem significações explícitas nem ideias claras, só existem sentidos implicados nos signos [...]. Só procuramos a verdade no tempo, coagidos e forçados. Quem procura a verdade é o ciumento que descobre um signo mentiroso no rosto da criatura amada; é o homem sensível quando encontra a violência de uma impressão; é o leitor, o ouvinte, quando a obra de arte emite signos, o que o forçará talvez a criar, como o apelo do gênio a outros gênios (DELEUZE, 2010, p. 9I).

A criação pura é, propriamente, a forma da tradução, do desenvolvimento, da decifração de um signo. Se a ideia é desenvolvida pelo pensamento, é na mesma medida em que a própria ideia já se encontra enrolada e envolvida no signo. Se a ideia vive no signo em estado obscuro, é, pois, por esse próprio estado oferecer uma violência tal que force o ato de pensar. É nessa medida que pensar tem a ver com encontros não pré-determinados, com a intensidade do acaso, mas a necessidade do pensamento é garantida, precisamente, por essa contingência do encontro.

\section{v. Conclusão}

Proust e os signos se insere dentro das relações entre a filosofia de Deleuze e saberes de outros domínios, nesse caso: a arte, mais especificamente, a literatura. 
Deleuze investiga o tempo e o pensamento em seus envolvimentos com o signo, através da leitura de Em busca do tempo perdido, considerada pelo autor como uma espécie de odisseia filosófica (mesmo que crítica em relação à filosofia), de uma busca involuntária pela verdade. O envolvimento de Deleuze com a arte, nessa abordagem, é duplo, na medida em que além de pensar a obra de um literato, a pensa do ponto de vista da arte, e de um artista que coloca a arte numa posição superior à filosofia. A arte teria mais valor que a filosofia, já que mais importante que o pensamento seria aquilo que faz pensar.

Fazer pensar é a questão da arte e, para Deleuze, o papel da arte como impulsionadora do ato do pensamento é algo primordial, haja vista que o filósofo francês, quando investiga o que significa pensar, se importa, sobretudo, com os elementos anteriores ao exercício do pensamento, ao campo pré-filosófico, pré-conceitual e até mesmo pré-individual. Dentre os diferentes regimes de signos (os mundanos, os amorosos, os sensíveis), os artísticos são os superiores por darem sentido a todos os outros. E o encontro entre o signo artístico e seu sentido é perfeitamente adequado por sua característica espiritual, imaterial, "autônoma". Mas a principal importância da arte nesse contexto, em meio às ideias expostas na recherche, é a de sua potência para a crítica à imagem dogmática do pensamento.

A imagem dogmática do pensamento pressupõe que o pensamento seja algo da ordem do natural, baseado na boa vontade do pensador. Deleuze quer então mostrar, procurando aliados na filosofia de Nietzsche e na literatura de Proust (dentre outros), que para pensar não basta o esforço pessoal ou o acesso de uma faculdade por um "eu". Que o pensamento aparece coagido, determinado por forças de fora, forças provindas de encontros contingentes que, no entanto, asseguram a necessidade do pensamento. É assim que se busca ultrapassar a condição de possibilidade posta ao pensamento pela razão. De onde, após a crítica, em vistas de se instalar uma nova imagem do pensamento, talvez a questão mais forte não seja mais a pergunta pelo que significa pensar ou mesmo pelo que faz pensar, mas sim a questão: como pensar o ainda impensado?

\section{Referências bibliográficas}

DELEUZE, Gilles. Diferença e repetição. Rio de Janeiro: Graal, 2006. - Nietzsche e a filosofia. Rio de Janeiro: Editora Rio, I976.

Proust e os signos. Rio de Janeiro: Forense Universitária, 2010. ; GUATTARI, Félix. O que é a flosofia?. Rio de Janeiro: Editora 34, I992. 
PROUST, Marcel. A fugitiva. Rio de Janeiro: Ediouro, 2004b. (Em busca do tempo perdido, v. III).

. No caminho de Swann. Rio de Janeiro: Ediouro, 2004a. (Em busca do tempo perdido, v. I).

. Sodoma e Gomorra. Rio de Janeiro: Ediouro, 2004c. (Em busca do tempo perdido, v. II).

MACHADO, Roberto. Deleuze, a arte e a filosofia. Rio de janeiro: Jorge Zahar, 2010.

NIETZSCHE, Friedrich. Além do bem e do mal: prelúdio a uma filosofia do futuro. São Paulo: Companhia das Letras, 1999.

RAJCHMAN, John. As ligações de Deleuze. Lisboa: Temas e Debates, 2002.

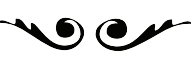

Leonardo Araújo Oliveira - Graduado em Filosofia pela Universidade Estadual do Sudoeste da Bahia. leovash5@gmail.com 